Conclusions: Unlike current guidelines, in clinical practice a long-term treatment with GCs is often necessary in PMR. There is need to investigate novel treatments for PMR. This preliminary data suggests that aminobisphoshonates may have a role in the management of PMR.

Disclosure of Interest: None declared

DOI: 10.1136/annrheumdis-2018-eular.3055

\section{THU0435 LONG-TERM OUTCOME AND PROGNOSIS FACTORS OF COMPLICATIONS IN THROMBOANGIITIS OBLITERANS (BUERGER'S DISEASE): A MULTICENTER STUDY OF 224 PATIENTS}

A. Le Joncour ${ }^{1}$, S. Soudet ${ }^{2}$, A. Dupont ${ }^{3}$, O. Espitia ${ }^{4}$, F. Koskas ${ }^{5}$, P. Cluzel $^{6}$, P.Y. Hatron ${ }^{2}$, P. Cacoub ${ }^{1}$, M. Resche-Rigon ${ }^{3}$, M. Lambert ${ }^{2}$, D. Saadoun ${ }^{1}$.

${ }^{1}$ Département de médecine interne et immunologie clinique, Hôpital de la Pitié Salpêtrière, Paris; ${ }^{2}$ Département de Médecine Interne et Immunologie Clinique, CHU Lille, Lille; ${ }^{3}$ Département de Biostatistiques, CHU Saint Louis, Paris;

${ }^{4}$ Département de Médecine interne, CHU Hôtel Dieu, Nantes; ${ }^{5}$ Département de chirurgie vasculaire; ${ }^{6}$ Département d'imagerie cardio vasculaire et

interventionnelle, Hôpital de la Pitié Salpêtrière, Paris, France

Background: Buerger's disease or thromboangiitis obliterans (TAO) is a nonatherosclerotic arteritis of distal extremities. Data regarding long term outcome of patients with Buerger's disease or thromboangiitis obliterans (TAO) are lacking and most series come from Middle-East and Far-East.

Objectives: We aim report clinical presentation and assess long-term outcome and prognosis factors in a large cohort of TAO.

Methods: Retrospective multicenter study of characteristics and outcomes of 224 TAO patients fulfilling Papa's and/or 5 Shinoya's criterias were analysed. Factors associated with vascular event free survival and amputation free survival were identified.

Results: The median age at diagnosis was $38.5^{32-46}$ years, 51 (28.5\%) patients were female and $81.5 \%$ were Caucasians. All but 3 were smokers with a median of 22 pack-year and $22.8 \%$ were also addict to cannabis. At diagnosis, $53 \%$ had claudication, $73 \%$ trophic disorders and $8.8 \%$ an infection. Lower extremities and upper extremities were affected in $54 \%$ and $28 \%$ respectively. Superficial vein thrombosis, Raynaud's phenomen and arthralgia occurred in $18 \%, 41 \%$ and $8 \%$, respectively.

Ethnic group (non-Caucasian) and ischaemic ulcers or necrosis were independent factors of vascular events $H R=7.67$ [3.1-19.2] $p=0.005$ and 2.28 [1.34] $p<0.001$. At 15 years, amputation-free survival and major amputation-free survival were $66 \%$ and $91 \%$, respectively. Infection was the only independent predictive factor of amputation $\mathrm{HR}=4.6[1.9-11], \mathrm{p}<0001$. Age, sex and cannabis addiction were not associated with events or amputation. Patient who stopped their tobacco consumption had lower vascular event $(p=0.029)$ and amputation rate $(p=0.001)$ than those who continued. Three patients died during follow-up. Conclusions: This nationwide study shows that $34 \%$ of TAO patients will experience an amputation within 15 years from diagnosis. We identified specific characteristics that identified those at highest risk for subsequent vascular complications.

Disclosure of Interest: None declared

DOI: 10.1136/annrheumdis-2018-eular.2317

\section{THU0436 INCIDENCE, PREVALENCE, MORTALITY AND CHRONIC RENAL DAMAGE OF ANCA-ASSOCIATED GLOMERULONEPHRITIS IN A 20 YEAR POPULATION- BASED COHORT}

A. Berti ${ }^{1,2}$, E. Cornec-Le Gall ${ }^{3}$, D. Cornec ${ }^{4}$, E. Matteson ${ }^{5}$, C.S. Crowson ${ }^{6}$, S. Sethi ${ }^{3}$, F. Fervenza ${ }^{3}$, U. Specks ${ }^{4}$. ${ }^{1}$ Unit of Immunology, Rheumatology, Allergy and Rare Diseases, IRCCS San Raffaele Scientific Institute, Milan; ${ }^{2}$ Rheumatology Clinic, Santa Chiara Hospital, Trento, Italy; ${ }^{3}$ Nephrology Department, ${ }^{4}$ Pulmonary and Critical Care Medicine; ${ }^{5}$ Rheumatology Department, ${ }^{6}$ Division of Biomedical Statistics and Informatics, Mayo Clinic, Rochester, USA

Background: True population-based incidence rates of ANCA-associated glomerulonephritis (AAGN) are lacking

Objectives: We aimed to estimate incidence, prevalence and mortality of AAGN, and to assess if the grade of chronic renal damage at presentation predicts renal and non-renal outcomes.

Methods: A population-based incident cohort of 57 Olmsted County residents diagnosed with ANCA-associated vasculitis (AAV) in 1996-2015 was identified by medical record review. AAGN was defined as an increase in creatinine $>30 \%$ and/or a decrease in estimated glomerular filtration rate $>25 \%$, and/or the presence of urine red cell casts or hematuria and/or biopsy-proven necrotizing and/or crescentic glomerulonephritis. Incidence rates were age- and sex-adjusted to the 2010 US white population. Age- and sex-adjusted prevalence was calculated for January 1, 2015. Survival rates were compared with expected rates in Minnesota population. Chronic renal damage was assessed by chronicity score (CS) on biopsies performed at diagnosis.

Results: Thirty-four (60\%) patients had AAGN. Of these, $65 \%$ had microscopic polyangiitis (MPA), and 74\% were myeloperoxidase (MPO)-ANCA-positive. The annual incidence of AAGN was $2.0 / 100,000$ population (95\% $\mathrm{Cl}: 1.3-2.7$ ), the overall prevalence was 35/100,000 (95\%Cl:24-47). Mortality for AAGN was increased $(p<0.001)$, whereas mortality for AAV without glomerulonephritis did not differ from the general population. Minimal/mild CS predicted recovery of renal function at 1 year $(\mathrm{p}=0.035$; figure $1 \mathrm{~A}$ ); clinical diagnosis (granulomatosis with polyangiitis (GPA) versus MPA) and ANCA-specificity (proteinase 3(PR3)-AAV versus MPO-AAV) did not (figure 1B-C).
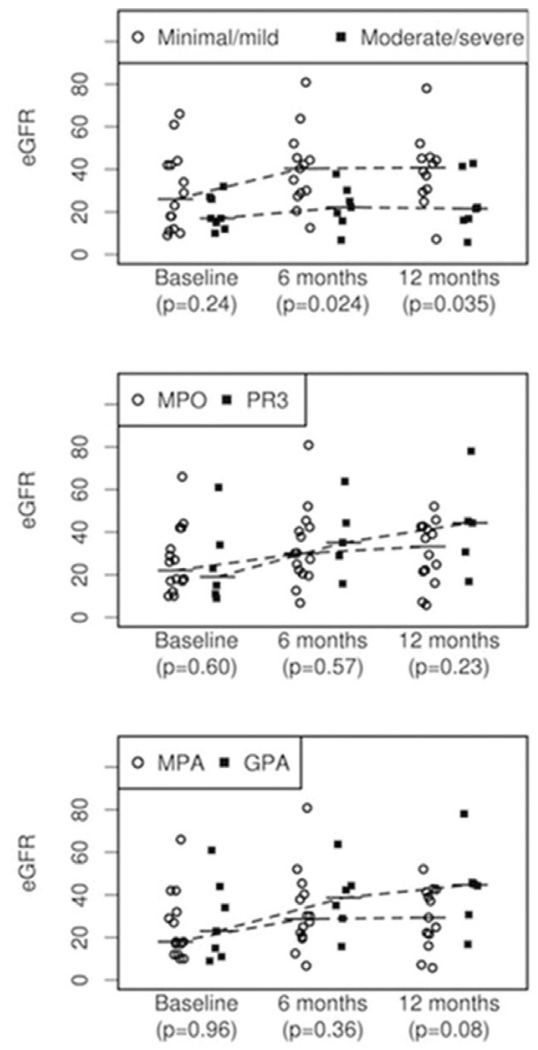

Conclusions: Annual incidence and prevalence of AAGN in Minnesota are 2.0/ 100,000 and $35 / 100,000$, respectively. Mortality is worse compared to AAV patients without glomerulonephritis. More advanced renal damage at diagnosis predicts less renal recovery.

\section{REFERENCES}

[1] Berti A, Cornec D, Crowson CS, Specks U, Matteson EL. The epidemiology of ANCA associated vasculitis in Olmsted County, Minnesota (USA): a 20 year population-based study. Arthritis \& rheumatology (Hoboken, NJ) 2017

[2] Sethi S, D'Agati VD, Nast CC, Fogo AB, De Vriese AS, Markowitz GS, et al. A proposal for standardized grading of chronic changes in native kidney biopsy specimens. Kidney international 2017;91(4):787-9.

Disclosure of Interest: None declared

DOI: 10.1136/annrheumdis-2018-eular.7285 